Trivent Publishing

(C) The Authors, 2016

Available online at http://trivent-publishing.eu/

Engineering and Industry Series

Volume Power Systems, Energy Markets and Renewable Energy Sources in

South-Eastern Europe

\title{
Possible Role and Effects of Synthetic Inertia on the Future's Power System
}

\author{
Istvan Taczi, Istvan Vokony \\ Department of Electrical Power Engineering, Faculty of Electrical Engineering and \\ Informatics, University of Technology and Economics, Hungary \\ vokony.istvan@vet.bme.hu
}

\begin{abstract}
The growing share of renewable energy sources leads system operators to previously-unknown challenges. Beside the well-known issues of balancing and capacity adequacy, the security of supply, reliability and stability are also essential and the electric power grid's operation must meet the expectations. Some of the emerging technologies are connecting to the grid via power converters so they are practically decoupled from the system and its frequency changes. The electric power system has not been designed for that: stability relied heavily on the inertial response of synchronous generators which decreases the rate of change of frequency (ROCOF). The rotating mass of those generators is directly coupled to the system and functions as a kinetic energy storage component which was incredibly useful. Renewable energies such as wind and solar have to be augmented with synthetic inertia to provide such a useful function otherwise stability issues, load shedding and outages will occur. The questions are so current that ENTSO-E listed this problem as one of three main focus topics in their research and development plan from 2015 to 2017 so the transmission system operators across Europe are all thinking about the possibilities. This study introduces the policy, physical and technical background, the possible role of the implemented synthetic inertia and also provides simulation results for further understanding.
\end{abstract}

This is an Open Access article distributed in accordance with the Creative Commons Attribution Non Commercial (CC-BY-NC-ND 4.0) license, which permits others to copy or share the article, provided original work is properly cited and that this is not done for commercial purposes. Users may not remix, transform, or build upon the material and may not distribute the modified material (http://creativecommons.org/licenses/by-nc/4.0/) 


\section{Keywords}

Synthetic inertia; Power system stability; Frequency control; Renewable energy

\section{Background}

The electric power system operators will face enormous challenges in the near future. The growing share of renewable energy resources brings high amount of intermittent and decentralized generation. This procedure has effects on the entire value chain of the power grid and some of those are even unknown right now. The pace of change is exponential as it can be seen in Figure 1. According to the International Renewable Energy Agency, the 1,828 GW generation capacity of those resources is commeasurable with the 1,500 $\mathrm{GW}$ from gas power stations and the 1,880 GW from coal-fired power plants. In Denmark, renewable energy sources provided 39\% of the electricity generation in 2014, and in some cases there were countries where renewable provided $100 \%$ of the demand for a short period of time. While these resources reduce the burden on the environment in many ways, the integration process to the system is not so easy from a technical point of view. The transmission and distribution grid need to be more flexible as well as the reserve capacities to provide balancing. The long- term generation adequacy for a sustainable system is also a key issue and has to be planned carefully. Even if the constraints are met, the operation and controlling methods have to be adjusted to this whole new decentralized structure with variable generation. But the policy goals are clear; the world must lean on clean energy. Therefore, new trends and solutions will emerge to evolve a sustainable power system for the future [1].

Renewable energy sources such as wind and solar use different technologies than conventional power plants. Their electrical characteristics and controlling methods have to be considered by system operators to control the system effectively. Some renewable energy sources may still use a thermal cycle for power production like conventional sources, but most of the wind and solar generating units connect to the grid via power electronic based converters. This means that they are practically decoupled from the grid and its frequency excursions. This means that the conventional active power control parameters change radically. The stability of the system could become a major concern [16] [27]. 


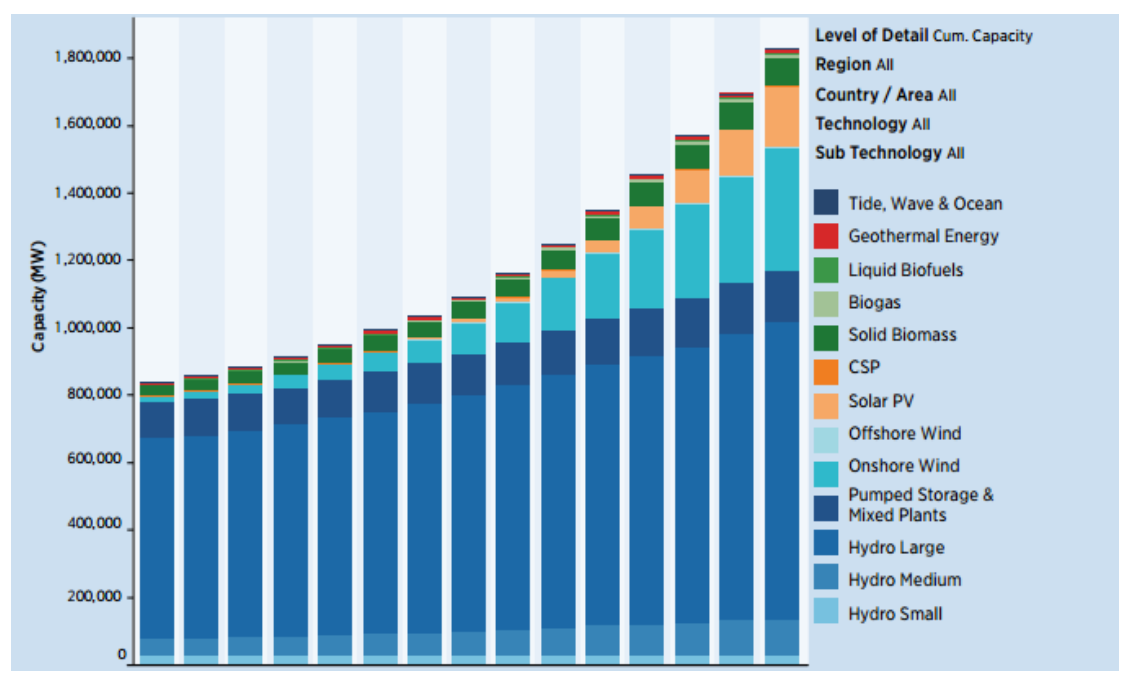

Fig. 1. Installed renewable energy capacity in the countries monitored by the International Renewable Energy Agency [IRENA] from 2001 to 2015

\section{The active power - frequency response}

The main task of system operators is to maintain the voltage and frequency in the electrical grid for stable operation. When the consumption rises rapidly or a large generating plant shuts down, the frequency of the grid drops because of the imbalances in the active power production and load. Figure 2 shows frequency regulation scheme: the three main categories, the main signals and feedbacks which used. The difference between those is the time required to take action. But even before primary control reacts to changes, there is a physical response of the grid-connected synchronous generators which is called inertial response. This is a key factor in slowing the rate of change of frequency (ROCOF) in the early stage of a frequency deviation. This physical response is coming from the conventional synchronous machines which contribute stored kinetical energy by its rotating mass [1][16][27]. 


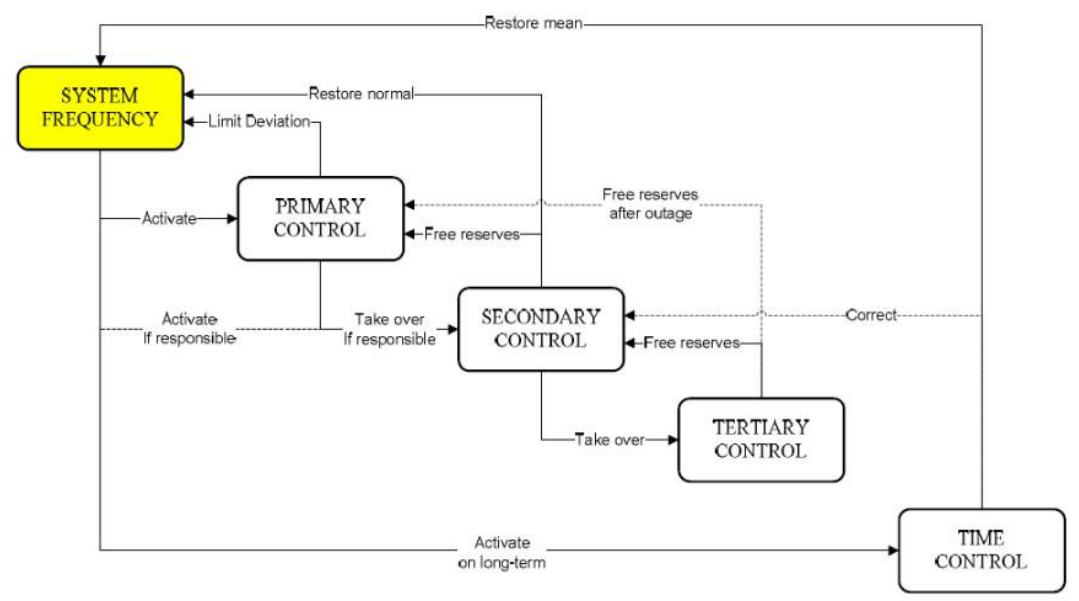

Fig. 2. Scheme of the levels of frequency regulation [ENTSO-E]

After the first few seconds, the primary control is being activated and governors of the synchronous machines increase their mechanical power output to stop the frequency change and reach an equilibrium in active powers at a certain level. Secondary control is responsible to set the frequency as close to the nominal as possible, as it can be seen on Figure 3 [16] [27].
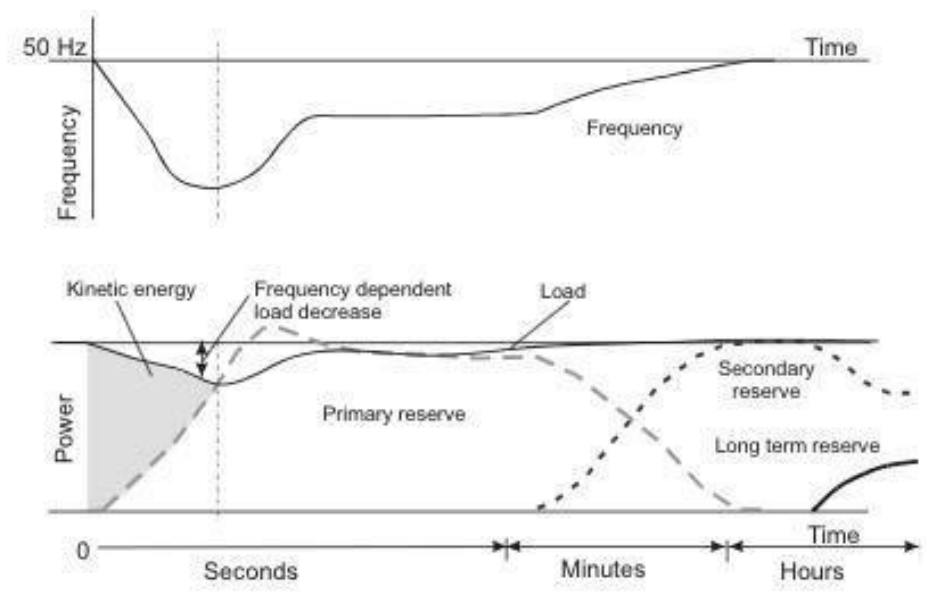

Fig. 3. Active power controlling during a frequency deviation [1]

With more generating units connecting to grid through power electronics, the frequency excursions could be deeper because they cannot provide inertial response. This could lead to devastating consequences for the security of supply and reliability [4].

Figure 4. shows the main indicators of a frequency excursion. The difference 
from the nominal value, the speed of the change and the minimum absolute value are important. From these, the frequency change could be evaluated from the stability viewpoint [2].

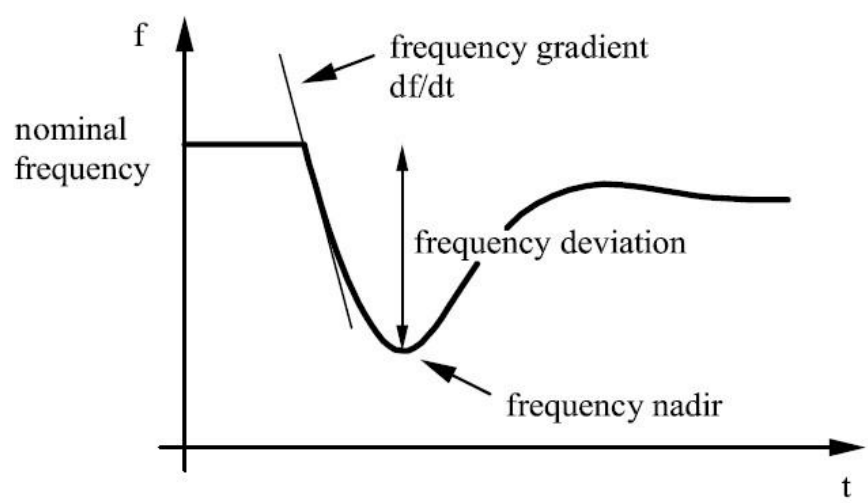

Fig. 4. Frequency response indicators [2]

\section{Definition of inertia and the swing equation}

The generated and consumed powers are equal in a static equilibrium:

$$
P_{\text {Gen }}=P_{\text {Mech }}=P_{\text {Load }}=P_{\text {Load }}+P_{\text {Loss }}
$$

Where $\mathrm{P}_{\mathrm{Gen}}$ is the active electrical power, and of all generating units connected to the grid, $\mathrm{P}_{\text {Mech }}$ is mechanical power of the connected turbines. $\mathrm{P}_{\text {Load }}$ is the total system load, $\mathrm{P}_{\text {Loss }}$ represents all system losses concentrated. (All in MW). During an outage (or a high ramp load increase) the system is in the dynamic equilibrium. During this dynamic process the swing equation represents the power equilibrium for a single machine:

$$
P_{m i}=P_{g i}+D_{i} * \Delta \omega_{i}+\frac{d E_{K I N i}}{d t}
$$

Where $D w_{i}$ is the unit's mechanical speed difference from the rated mechanical speed in $\mathrm{rad} / \mathrm{s}$. $\mathrm{D}_{i}$ is a damping parameter of the unit's rotor. The derivative of the kinetic energy stored in the rotating mass tries to mitigate the difference between the mechanical and electrical powers. This energy can be calculated from the rated power ( $\mathrm{S}$ in $\mathrm{MW})$ and the inertia constant $(\mathrm{H}$ in s) of the rotating unit:

$$
E_{K I N i}=\frac{1}{2} J * \omega_{n}^{2}=H_{i} * S_{i}
$$

Where $w_{n}$ is the nominal frequency of the system and $J$ is the moment of 
inertia in $\mathrm{kg} \times \mathrm{m} 2$. The inertia constant determines the ROCOF with the externalities (increased $\mathrm{H}$ reduces the angular acceleration) so it can be recalculated from it if the power imbalance and the instant of the change is known:

$$
H_{i}=\frac{\Delta P_{i}\left(t_{0}\right) f_{n}}{\left.2 \frac{d f f_{i}}{d t}\right|_{t=t_{0}}}
$$

All of the values refer to generator named $i$. The inertia of a whole system is the combined inertia of each spinning generation and load as well. If the share of synchronous machines in the generation mix decreases, the inertia will be lower. This could lead to higher amplitude and longer swings or even outages [4].

$$
S_{n} H=S_{n 1} H_{n 1}+S_{n 2} H_{n 2}+\cdots+S_{n m} H_{m}
$$

\section{Technological possibilities to provide synthetic inertia}

The concept of synthetic inertia is to control the power converters like they have rotating mass. This simulates the natural response of the synchronous machines. There are several ways to implement this, this chapter summarizes the renewable energy related solutions. However, the natural power absorption and extraction could not be emulated perfectly and those feedbacks may result in oscillating power which could wear the mechanical elements of the device, so the optimal controlling parameter identification is a major objective.

\section{A. Wind energy}

Wind turbines do have moving parts, therefore they store kinetic energy in the rotating blades. The fixed speed types cannot be controlled effectively and that withheld the spreading of this technology. Variable speed wind turbines (VSWT) have power electronics and easy to control. There are two main types, the doubly-fed induction machine (DFIG, type 3 ) and the full converter type (FC, type 4). Despite having no natural inertial response, the kinetical energy of the rotating blades could be used for a synthetic inertia control. The controlling methods could be implemented as an additional feedback loop for the converter. This forms a power set signal from the measured frequency values to emulate the inertial response. If the frequency is lower than the nominal, the controlling extracts additional energy with torque increase, which slows the rotation of the blades (first it is aerodynamic power, after that it is the kinetic energy of the spinning rotor). This could be used in the opposite direction too, when the frequency is over the nominal value. The technical constraints and limits like the rotation speed and the converters scale must not be excessed. The loss of the possible wind energy input is low, below $1 \%$ in MW scale installations 
according to several studies. The inertia constant of wind turbines varies between 2-6 s which is comparable to the synchronous generations 2-10 s [14] [4] [1].

\section{B. Solar energy}

A photovoltaic system has no moving parts. Therefore - if it is unmodified - it is unable to provide any kind of inertial response. The converters usually try to maximize the energy extraction in those systems. Another problem is that the power electronics only connect the unit to the grid in a narrow frequency line and if the frequency goes outside this band, the converter isolates it from the system for protection purposes. However, the power electronics could optimize the power flow, if the generation unit is augmented with an equipment that can store energy some way. A wide-range of energy storage applications has the parameters to be able provide this kind of support. The easiest choice is a flywheel system which works just the same as the synchronous machines rotating mass. Supercapacitors and batteries also have the fast response time that needed. With an optimum size aggregated system of storage technologies, the additional capacity could be added with optimal controlling parameters [1][6].

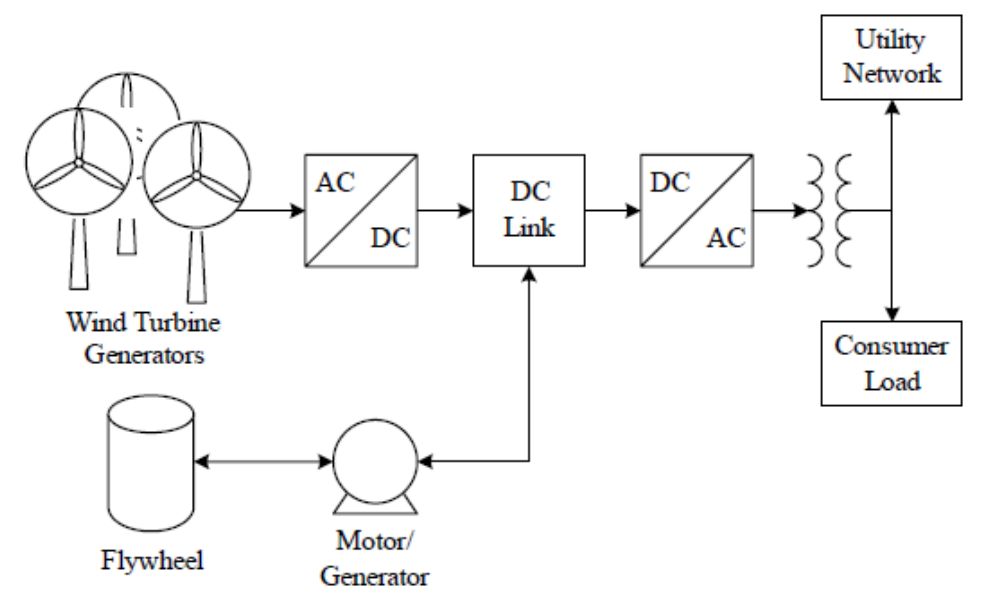

Fig. 5. Schematic of a possible utilization of a storage system [6]

\section{Direct current (DC) networks}

DC networks have some interesting upsides regarding to stability. The aligned controlling of the decentralized generators in microgrid concepts brings the opportunities to utilize the DC side more effectively. The power electronics - if equipped with proper communication systems - could form and control grid conditions with more intelligent controlling algorithms. 
Another intriguing solution for synthetic inertia through voltage source converter is high voltage direct current (VSC- HVDC) transmission system with DC link capacitors. The HVDC control system can be modified to be capable of emulating wide-range of inertia time constants using relatively small constant capacitances connected to the DC circuit [24].

\section{Controlling principles of synthetic inertia}

Synthetic inertia needs some kind of energy storage to be able to change the active power output for a short period of time. Since it is not a natural response, the use of the stored energy has to be controlled and it is based on the grid frequency. The following examples are from wind energy studies but it is extensible for all synthetic inertia controlling methods. The most obvious way to emulate the inertial response is adding extra torque ( $\mathrm{T}$ ) proportional to the frequency change $(\mathrm{df} / \mathrm{dt})$.

$$
T=2 H \frac{d f}{d t}
$$

This solution could be influenced by noise and low frequency power oscillations after a disturbance, so proper filtering is crucial. It works well as an additional inertia source if there is synchronous generation with governor primary controls [2].

Another possibility to provide synthetic inertia is based on the calculation of the system frequency from the average of all connected generators rotating speed. The main drawback of this solution is definitely the involvement of communication systems to transfer the subsystem frequency data, but there are several ways for estimation (Kalman or FIR filter implementations) [2].

The output power change could be based on Df. This can be seen as a frequency supporting algorithm to maintain the grids nominal value. It has no effect on the $\mathrm{df} / \mathrm{dt}$ characteristics, but can improve the frequency nadir and it is also an important part to maintain the stable operation of the grid. This method also has lower mechanical stress effects compared to the $\mathrm{df} / \mathrm{dt}$ solution. The concept is that if the frequency falls below a limit the unit increase the active power. The time for overproduction is limited by the technical constraints and the accessible stored energy. The end time of this surplus must be considered because it could lead to even larger disturbances if the frequency falls again from a lower starting point - because the units are recovering the additional stored energy in the example of wind turbines [2].

One more example for synthetic inertia is that the active power in the operating point is less than the maximum (e. g. 3- 6\% of nominal power) and this power could be used as a traditional frequency support like droop control [2][4].

Each one of those methods has its pros and cons. A df/dt controller imitates the synchronous generation well, but could cause oscillations. The Df controller 
has to be set carefully to avoid overshoot or it will cause even larger disturbances. The output power curtailing loses more energy but can be seen and used just as the conventional spinning reserve [2][1].

\section{Test system for frequency analysis focusing on inertial response and primary control}

The following chapter introduces a simple dynamic model and RMS simulations conducted in DigSilent Power Factory v14.2 and v15.1 with the scope of analyzing the inertial response. The model on Figure 6 has two gas turbines (210 MVA built-in type with governors and automatic voltage regulators, inertia constant is 18,36 s) with $150 \mathrm{MW}$ and $50 \mathrm{MW}$ active power output, one concentrated general load at $120 \mathrm{kV}$ (100 MW active power consumption) and two concentrated general loads at $33 \mathrm{kV}$ with $50 \mathrm{MW}$ active power consumption each. The loads are dynamic, frequency-sensitive with $\mathrm{k}_{\mathrm{pf}}=1$ and $\mathrm{k}_{\mathrm{q} f}=-0,5$. The transformers are also built-in types with sufficient transmission capability to feed the loads. The external grid element is out of service, so this is an island model. All tests were RMS simulations with $40 \mathrm{~s}$ timespan, the events happened at $20 \mathrm{~s}$.

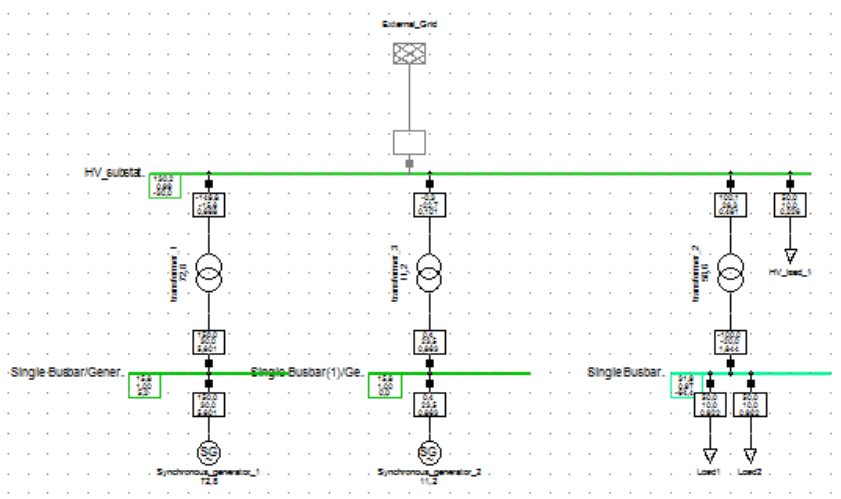

Fig. 6. The test system topology

\section{A. Increased load}

Figure 7 shows the change of the load. This is a rapid increase to $150 \%$ and that causes the frequency deviation. 


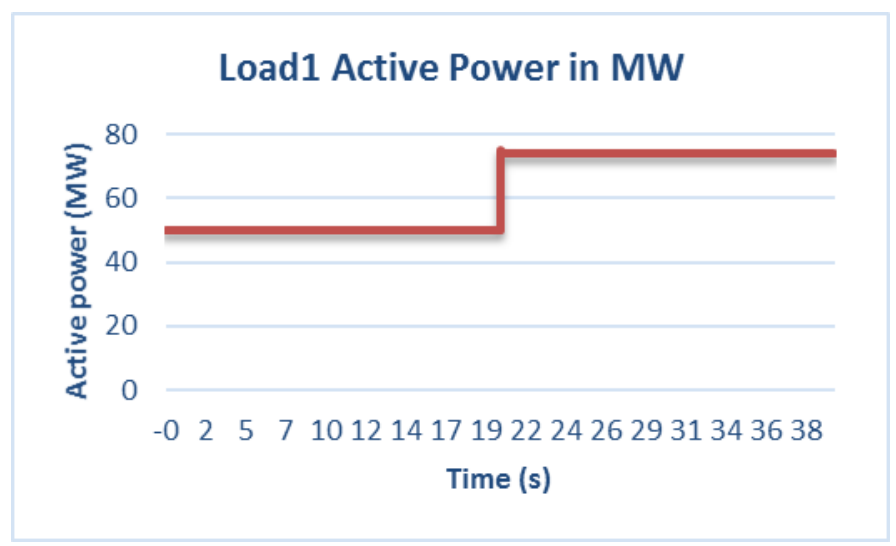

Fig. 7. Active power change of load

Figure 8 shows the frequency during the load increase event. From the starting ROCOF - as it was introduced in chapter III - the inertia constant of the system could be estimated. The frequency nadir is 49,839 Hz. Figure 9 shows the output of the generator during the disturbance. The governor provides primary control and meets the increased load at a lower frequency. This study did not considerate the effects of secondary control, the focus was just on the inertial response examples.

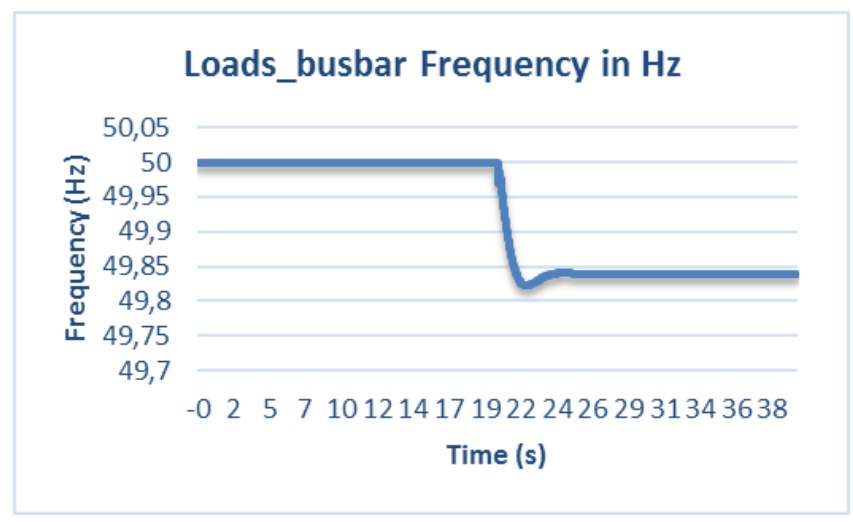

Fig. 8. Frequency deviation during the load increase 


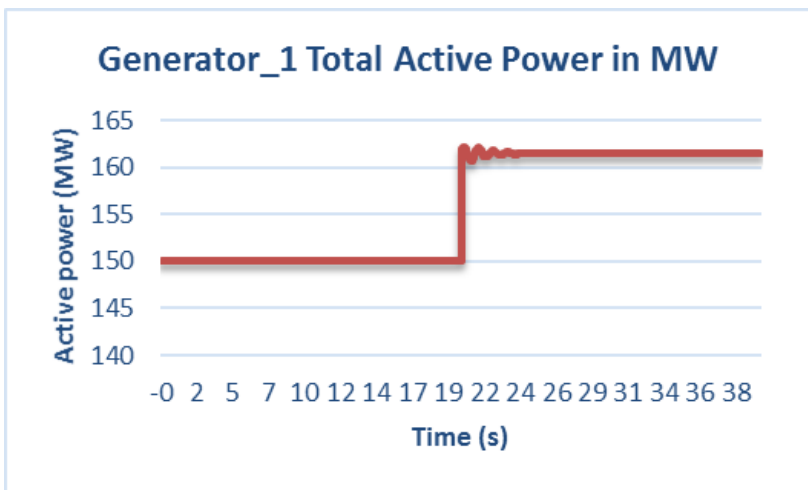

Fig. 9. Generator active power output change during a load increase

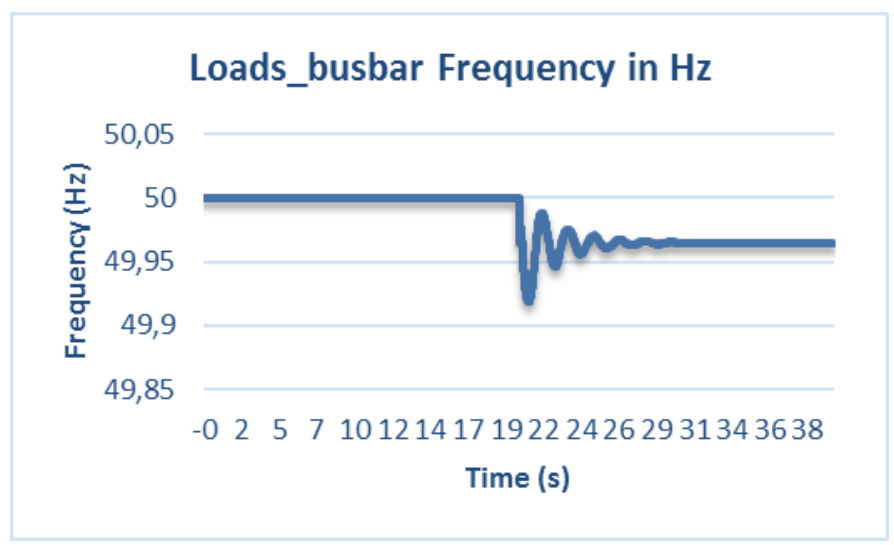

Fig. 10. Frequency during load increase with lower $\mathbf{R}$ parameter

In Figure 10, the governor of the generators has lower $\mathrm{R}$ parameter (gradient), therefore there are high amplitude swings in frequency and active power output of the generators. This could happen with the df/dt synthetic inertia controller if the parameters are wrong.

\section{B. Loss of generation}

A larger disturbance event could be an outage of a generation. With this parameters, the remaining generator could not serve the load and a system is collapsing (there were no frequency-based protections implemented on the loads or generators so they did not get decoupled, but it can be seen that one generation unit is insufficient in this case, as it can be seen on Figure 11. 


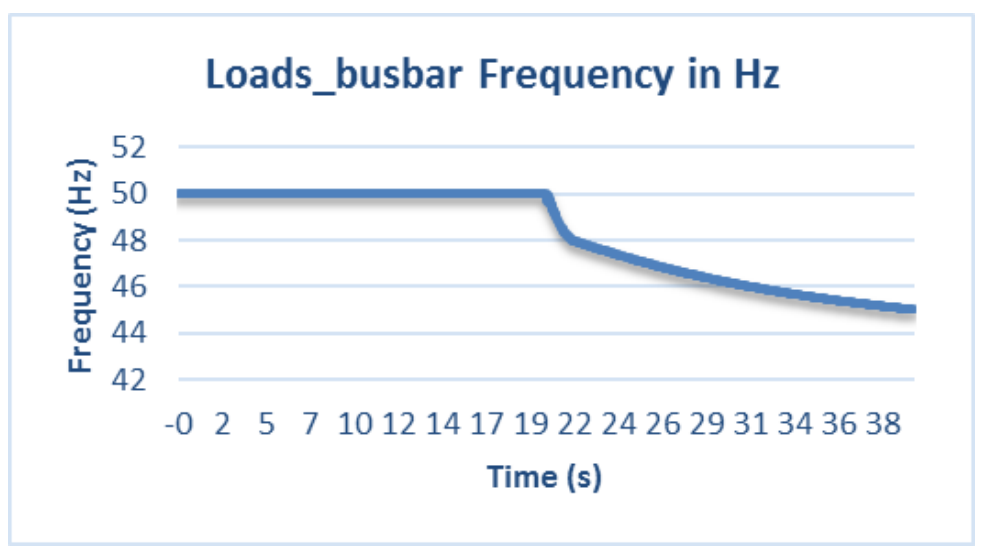

Fig. 11. Frequency collapse during an outage

\section{Automatic load shedding (ALS)}

ALS could be a solution for cases like VI/B when the supply could not meet the demand, but it is a drastic method. The purpose of the entire electric power system is to meet the consumer's expectations, therefore ALS should be used only in cases when the operator tries to save the system from an even bigger collapse. Figure 12. shows that in this case (the same as VI/B, a generator outage) the generation was adequate, but the load shedding cut off the entire 100 MW of the concentrated general load connected to the $120 \mathrm{kV}$ busbar. Additivity in ALS system could be a perfect match for synthetic inertia from decoupled energy sources: in this case the operator could use both sides of the supply chain effectively.

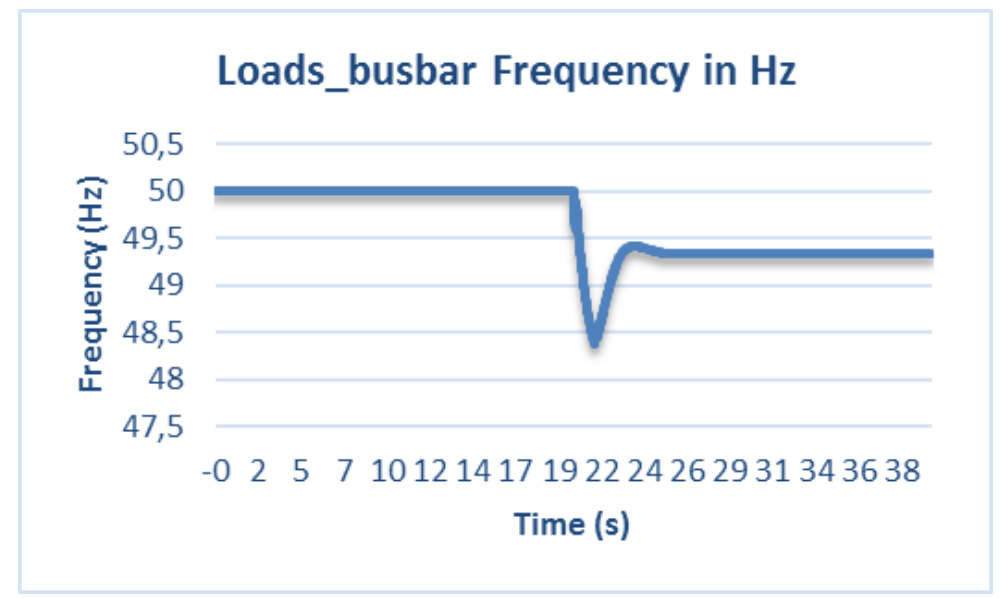

Fig. 12. ALS during outage 


\section{Renewable energy sources}

In this case, one of the gas turbine is replaced by the built-in wind turbine type with the same active power output (e.g. offshore wind farm). The renewable generator's power converter is controlled to maximize the extracted energy, therefore the ROCOF is higher and the nadir is also well below the values we got in VI/A with the same constraints. That means that the synthetic inertia control is needed when renewables have significant share of the generation.

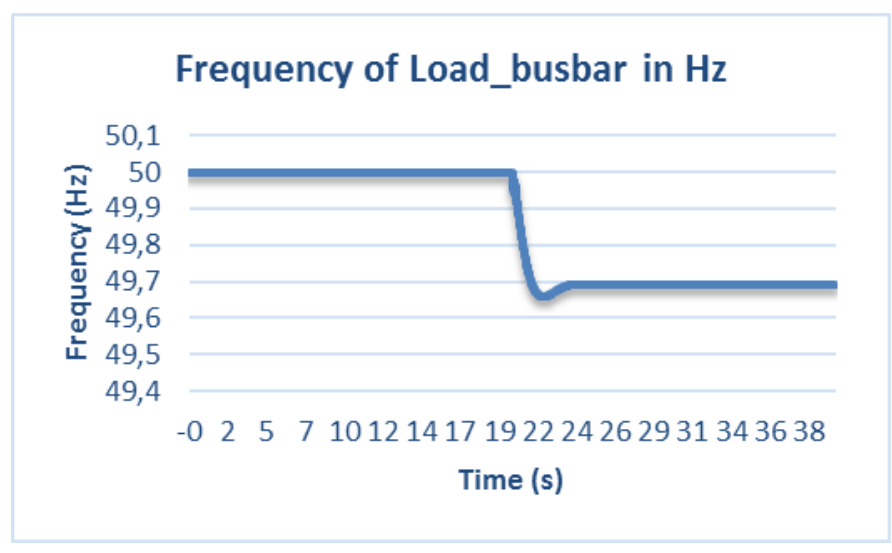

Fig. 13. Frequency deviation from load increase with high amount of wind power

\section{Conclusions}

With the spreading of energy sources connected to the grid via power electronics it is important to consider the changes in natural inertial response. The questions are so actual that ENTSO-E listed this problem as one of three main focus topics for research and development from 2015 to 2017 so the transmission system operators across Europe are all thinking about the possibilities. There are some technical opportunities that can use the elements of the wind turbine or a storage device to emulate the process. As it can be seen in chapter V., there is no optimal solution for frequency support through power electronic device controlling. The natural inertia response emulation - if the controlling parameters are identified correctly - could be used to avoid automatic load shedding in some cases, but a proper system control with acceptable security of supply and reliability of the system is far more complex from the ones introduced here. The ALS also should be reviewed and modified to be more adaptive to the changes. It should affect the minimum load and must not lead to further consequences such as high amplitude angular swings.

System approach is exceptionally important for further understanding of the ideal frequency support for tomorrow's sustainable power system. From the 
possible solutions and needs introduced in this study, a system-level frequency support could be conducted which includes the gradient, nadir, average difference parameter optimization and uses power electronic devices, adaptive load shedding methods and the maintained synchronous generation's primary and secondary control.

\section{References}

[1] Trent Ratzlaff. Effects Future Renewable Installations will have on System Synchronous and Synthetic Inertia. Master Thesis, Delft University of Technology, http://repository.tudelft.nl/islandora/object/uuid:1c94be1d3619-40a1-86fa-4a93941cce50? collection=education 2012.

[2] Johan Björnstedt. Integration of Non-Synchronous Generation. Doctoral Dissertation, Lund University, http://lup.lub.lu.se/record/2536665 2012.

[3] IEEE/CIGRE Joint Task Force on Stability Terms and Definitions. Definition and Classification of Power System Stability. IEEE Transactions on Power Systems, 2004.

[4] F. Gonzalez-Longatt, E. Chikuni, E. Rashayi. Effects of the Synthetic Inertia from Wind Power on the Total System Inertia after a Frequency Disturbance. Proceedings of the 2013 IEEE International Conference on Industrial Technology (ICIT), IEEE, 2013.

DOI: 10.1109/ICIT.2013.6505779

[5] Toshio Inoue, Haruhito Taniguchi, Yasuyuki Ikeguchi, Kiyoshi Yoshida. Estimation of Power System Inertia Constant and Capacity of Spinningreserve Support Generators Using Measured Frequency Transients. IEEE Transactions on Power Systems. Vol. 12, no. 1, 1997.

[6] Gauthier Delille, Bruno Francois, Gilles Malarange. Dynamic Frequency Control Support by Energy Storage to Reduce the Impact of Wind and Solar Generation on Isolated Power System's Inertia. IEEE Transactions on Sustainable Energy. Vol. 3, Issue 4, 2012. DOI: 10.1109/TSTE.2012.2205025

[7] Andreas Ulbrig, Theodor S. Borsche and Göran Andersson. Impact on Low Rotational Inertia on Power System Stability and Operation. Presented at IFAC World Congress 2014, Capetown, South Africa.

[8] National Renewable Energy Laboratory, Yingchen Zhang, Vahan Gevorgian, Erik Ela, Vikas Singhvi, Pouyan Pourbeik. Role of Wind Power in the Primary Frequency Response of an Interconnection, www.nrel.gov/docs/fy13osti/58995.pdf 2013.

[9] Gonzalez Longatt. Activation schemes of synthetic inertia controller on full converter type wind turbine (type 4). IEEE: Loughborough University Institutional Repository, 2015. DOI: 10.1109/PESGM.2015.7286430

[10] IEEE Power System Dynamic Performance Committee, Power System Stability Controls Subcommittee, Benchmark Systems for Stability 
Controls Task Force, Benchmark Systems for Small-Signal Stability Analysis and Control. IEEE PES Technical Report PES-TR18, 2015.

[11] Power System Dynamic Performance Committee, Power System Stability Subcommittee, Test Systems for Voltage Stability and Security Assessment Task Force. Test Systems for Voltage Stability Analysis and Security Assessment. IEEE PES Technical Report PES-TR19, 2015.

[12] H.R. Chamorro, M. Ghandhari, R. Eriksson. Wind Power Impact on Power System Frequency Response. Presented at the North American Power Symposium, 2013.

[13] Slavomir Seman, Raimo Sakki (ABB). Inertial response - generators and the power electronics, Active Power Control from Wind Power Workshop. Boulder, Colorado, 2011.

[14] Adam Stock, William Leithead. Providing Grid Frequency Support Using Variable Speed Wind Turbines with Augmented Control. EWEA Conference, Copenhagen, 2012.

[15] Lisias V. L. Abreu, Mohammad Shahidehpour. Wind Energy and Power System Inertia. IEEE PES General Meeting, Montreal, 2006.

[16] Jacob Aho, Andrew Buckspan, Jason Laks, Yunho Jeong, Fiona Dunne, Lucy Pao, Paul Fleming, Matt Churchfield, Kathrin Johnson. Tutorial of Wind Turbine Control for Supporting Grid Frequency through Active Power Control. Proceedings of the American Control Conference, 2012.

[17] Francisco M. Gonzalez-Longatt. Effects of the Synthetic Inertia from Wind Power on the Total System Inertia: Simulation Study. 2nd International Symposium on Environment-Friendly Energies and Applications EFEA, Newcastle, United Kingdom, 2012.

[18] Xueguang Wu, Yibin Zhang, Atputharajah Arulampalam, Nick Jenkins. "Electrical Stability of Large Scale Integration of Micro Generation into Low-voltage Grids." International Journal of Distributed Energy Resources 14 (2005): 299-320.

[19] Sudarshan Dahal, Nadarajah Mithulanathan, Tapan Kumar Saha. Assessment and Enhancement of Small Signal Stability of a Renewable Energy Based Electricity Distribution System. IEEE Transactions on Sustainable Energy, Vol. III, Issue 3, 2012. DOI: 10.1109/TSTE.2012.2187079

[20] M. Ribbens-Pavela, P. G. Murthy, J. L. Howard, J. L. Carpentier. "Transient Stability Index for On-line Stability Assessment and Contingency Evaluation." International Journal of Power and Energy Systems 4 (1982).

[21] DigSILENT Power Factory User Manual for version 14.2, 15.1., 2012. Available online at: http://www.digsilent.de/tl_files/digsilent/files/powerfactory/PowerFactory1 5/WhatsNew PF150.pdf (last time accessed: November $1^{\text {st }}$ 2016).

[22] Frei Teng, Goran Strabac. Evaluation of Synthetic Inertia Provision from Wind Plants. IEEE PES General Meeting, Denver, Colorado 2015. 
[23] Jan Van de Vyver, Jeroen D. M. De Kooning, Bart Meersman, Lieven Vandevelde, Tine L. Vandoorn. Droop Control as an Alternative Inertial Response Strategy for the Synthetic Inertia on Wind Turbines. IEEE Transactions on Power Systems. Vol. 31, Issue 2, 2016. DOI: 10.1109/TPWRS.2015.2417758

[24] Xudan Liu, Andreas Lindemann. Coordinated Control of VSC-HVDC Connected Offshore Windfarms for Enhanced Ability of Providing Synthetic Inertia. IEEE $6^{\text {th }}$ Symposium on Power Electronics for Distributed Generation Systems PEDG, Aachen, Germany, 2015.

[25] Thibaut Kovaltchouk, Vincent Debusschere, Seddik Bacha, Mirko Fiacchini, Mazan Alamir. Assessment of the Impact of Frequency Containment Control and Synthetic Inertia on Intermittent Energies Generators Integration. $11^{\text {th }}$ Conference on Ecological Vehicles and Renewable Energies EVER, Monte Carlo, Monaco, 2016.

[26] European Network of Transmission System Operators for Electricity (ENTSO-E). Future System Inertia (Nordic Report), https://www.entsoe.eu/Documents/Publications/SOC/Nordic/Nordic report Future System Inertia.pdf

[27] E. Ela, V. Gevorgian, P. Fleming, Y. C. Zhang, M. Singh, E. Muljadi, A. Scholbrook, J. Aho, A. Buckspan, L. Pao, V. Singhvi, A. Tuohy, P. Pourbeik, D. Brooks, N. Bhatt. Active Power Controls form Wind Power: Bridging the Gaps, 2014. Available online at: http://www.nrel.gov/docs/fy14osti/60574.pdf (last time accessed: November $1^{\text {st }}, 2016$ ) 